\title{
Making caesarean myomectomy safe and feasible: a 12 year single center experience
}

\author{
Priti Agrawal $^{1 *}$, Rishi Agrawal², Anandi Lobo ${ }^{3}$, Jyotirmay Chandrakar ${ }^{4}$
}

\begin{abstract}
${ }^{1}$ Department of Obstetrics, Gynecology and Infertility, ${ }^{2}$ Department of General and Laparoscopic Surgery, ${ }^{3}$ Department of Pathology, ${ }^{4}$ Department of Anesthesia, Aarogya Hospital and Test Tube Baby Center, Raipur, Chhattisgarh, India
\end{abstract}

Received: 22 December 2020

Revised: 01 February 2021

Accepted: 02 February 2021

\section{*Correspondence:}

Dr. Priti Agrawal,

E-mail: drpritiagrawal15@gmail.com

Copyright: (c) the author(s), publisher and licensee Medip Academy. This is an open-access article distributed under the terms of the Creative Commons Attribution Non-Commercial License, which permits unrestricted non-commercial use, distribution, and reproduction in any medium, provided the original work is properly cited.

\section{ABSTRACT}

Background: To standardize our protocol of caesarean myomectomy to make it safe and feasible for all patients. Methods: This prospective study was conducted in Aarogya Hospital and test tube baby Centre, Raipur from $1^{\text {st }}$ January 2008 to $1^{\text {st }}$ August 2020. Total 45 patients who had documented fibroid in index pregnancy and consented for the procedure were included. B- Lynch sutures were prophylactically applied in all cases to prevent $\mathrm{PPH}$.

Results: Our maximum patients were between the age of 20-30 years (66.67\%) and $75.56 \%$ were primigravida. $44.45 \%$ cases were of intramural fibroids and in $53.34 \%$ cases the size of myoma was $>5 \mathrm{~cm}$. Malpresentation was seen in $15.56 \%$ cases. $62.22 \%$ myomas were removed through single incision. $33.33 \%$ patients had uneventful second CS with us with excellent scar healing in $93.33 \%$ cases. $20 \%$ cases had secondary infertility and are advised further evaluation to find cause of infertility.

Conclusions: The decision to proceed with elective myomectomy at time of CS should be approached with proper pre-operative evaluation of the patient, thorough counseling for hysterectomy if required, expert team, arrangement of blood and adequate correction of medical factors like anemia, hypertension, and diabetes mellitus. Prophylactic application of B -Lynch sutures in all the cases made a dramatic improvement in tone of uterus which we observed intra operatively.

Keywords: APH, Cesarean myomectomy, Cesarean hysterectomy, Cesarean section, Fibroids and pregnancy, PPH

\section{INTRODUCTION}

Uterine fibroids are often seen in pregnancy in $0.3-5 \%$ cases. Myomectomy at the time of a caesarean section (CS) has traditionally been discouraged due to fear of intractable hemorrhage, need for hysterectomy and increased post-operative morbidity. If myomectomy during caesarean delivery becomes a widespread practice, it could potentially eliminate the risk of multiple surgeries, aesthetic complications, costs of repeated operative procedure and hospitalization. There is lack of large studies on caesarean myomectomy (CM) demonstrating its safety, so many surgeons still remain in dilemma whether to perform CM or not. During last 20 years our technique, patient selection and experience gradually improved and in the past 12 years we have safely performed CM in 45 women who requested for the simultaneous removal of previously diagnosed fibroid during CS. In the last decade, there have been various reports suggesting the safety of the procedure and documenting various reasons for the removal of uterine fibroid during CS including prevention of necrobiosis, pain during pregnancy, unusual intra operative appearance of the tumor, to gain access to the baby in patients in whom fibroids are obstructing the lower uterine segment (LUS), with pedunculated and anterior 
uterine fibroids and when the fibroids cause difficulty with uterine wound closure thereby causing significant blood loss. Also, the enucleation of fibroid becomes technically easier in a gravid uterus due to flexibility of capsule. CM scar has a better healing as uterus in postpartum phase is adopted physiologically to control hemorrhage. As contractions and retractions of muscle fibres occur, the blood vessels are closed. Also, the onset of vascular changes for clot formation in placental bed, helps in stopping the bleeding. We would like to put all the steps adopted by us that had made our CM safe.

Aims and objectives of the study were to standardize our protocol of caesarean myomectomy to make it safe and feasible for all patients.

\section{METHODS}

This prospective study was conducted in Department of Obstetrics and Gynecology, Aarogya Hospital and Test Tube Baby Centre from 1st January 2008 to 1st August 2020. 45 patients who fulfilled the following criteria were included:

Documented fibroid during the index pregnancy by antenatal ultrasound.

\section{Delivery by Cesarean section}

Willingness for CS and Myomectomy.

No preexisting coagulopathy.

Hemoglobin. $\geq 10 \mathrm{gm} / \mathrm{dl}$ (Except in cases of Sickle cell anemia)

All cases underwent elective cesarean section by the same team as and when required. In all patients consent for myomectomy if required caesarean hysterectomy for intractable hemorrhage was taken. All other factors which would adversely affect fetal and maternal outcome were explained. In all cases 2 units of packed red cells were arranged. In all patients we had given $200 \mu \mathrm{g}$ of misoprostol tablet sublingually just prior to giving spinal or general anesthesia. Abdominal incision was given as per the size of myoma to be removed. Pfannenstiel incision was preferred. Incision over uterus was given in such a way that after delivery of fetus and placenta the myomas could be removed from the same site. All myomas including posterior wall and fundal were removed from the same incision. (Figure 1A) after applying gentle pressure from the myometrial surface which made the myoma prominent on the endometrial surface and gently enucleation could be done (Figure 1B and C). All incisions were made using electro cautery. If more than one incision was required as in cases of multiple sub serosal and pedunculated fibroids then purse-strings sutures were used as described by Lee JH. ${ }^{1}$ Suturing of myoma bed was done with interrupted sutures leaving behind no dead spaces. Approximation of all loose myometrial tissue was done using interrupted sutures from the myometrial surface in cases of large myomas. Oxytocin drip was given in each case. All incisions were closed using vicryl no. 1 on needle. (Figure 1D) Care was taken that number of incisions over uterus were kept minimum by approaching adjacent fibroid through the same incision in a tunnel like fashion. BLynch sutures were applied in all the cases using catgut no. 2 on $70 \mathrm{~mm}$ round bodied needle. ${ }^{2}$ In all our cases after completing the suturing we felt that adequate uterine tone has not been attained and if blood starts collecting in intra myometrial spaces that intractable hemorrhage would occur. After applying B-Lynch sutures we waited for adequate uterine tone which was achieved in all cases and then abdominal closure was done. While giving uterine incision we made it a point to give it transversely and if required extend it in J-shaped manner to upper uterine segment so that extension of incision to uterine arteries or cervix or vagina can be prevented. But in two cases of placenta previa extension occurred and to attain hemostasis we did uterine artery ligation also. We did not use upper segment incision in any case.

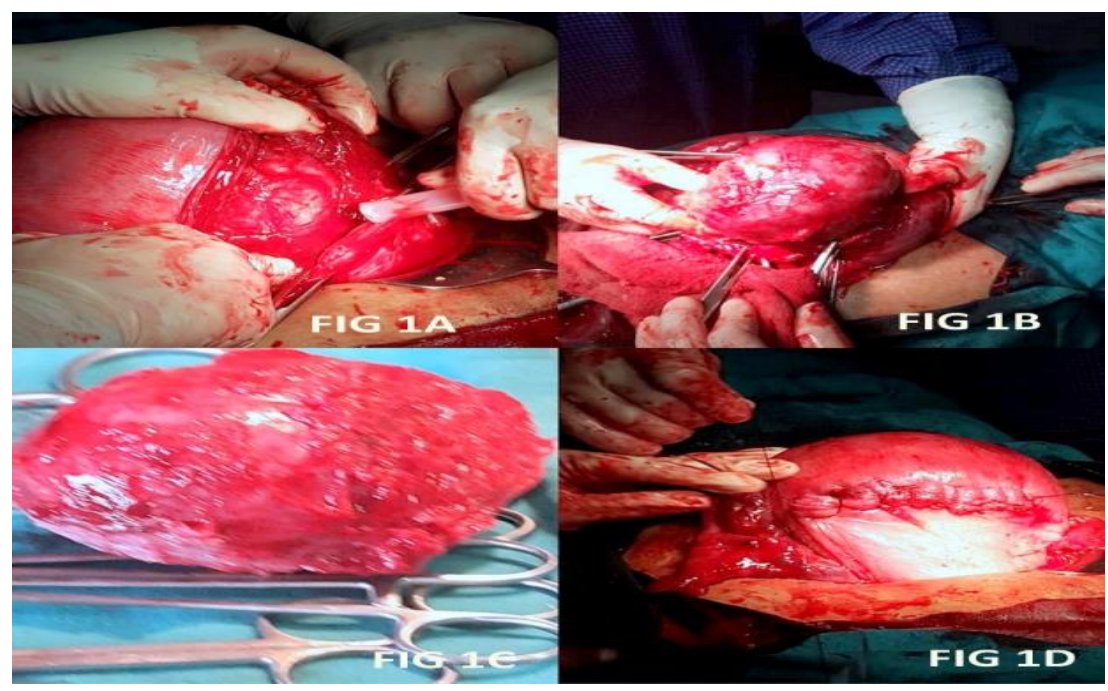

Figure 1 (A-D): Intraoperative images (A): Myoma (B): Enucleation (C): Myoma specimen (D): Uterine closure. 
If we felt that suturing would take prolonged time then we temporarily occluded the uterine and ovarian arteries using sponge holding forceps. We used suction to clear blood and fluids from the field rather than sponges. This has the advantage that operating field is not obscured and estimation of blood loss is accurate. Also, continuous long suturing was avoided as undue force may be applied by assistant leading to tearing of fibers. In post-operative period we monitored all the vitals of the patient, fundal height and bleeding per vaginum. But in all cases an abdominal ultrasound was done 6 hours post operatively to see any concealed clots or blood in the uterine and the peritoneal cavity. All patients were given antibiotic coverage till the day of discharge. Replacement of intra operative blood loss was done adequately. Stitches were removed on 8th post-operative day and repeat ultrasound was done to see involution of uterus and any intra peritoneal collection. At 6 weeks follow up patients keen for further child bearing were advised contraceptives for at least 2 years. All patients were counselled that if they had menorrhagia or severe abdominal pain at any point of time, they should immediately report back.

The SPSS version 22.0 software program was used for statistical analysis. No ethical approval was needed for this study.

\section{RESULTS}

Our maximum patients were between the age of $20-30$ years $(66.67 \%)$ and primigravida $(75.56 \%)$ (Table 1$)$.

Associated placenta previa was found in $22.2 \%$ cases and abruptio placenta in $6.67 \%$ patients. $26.65 \%$ cases were high risk for uterine atony. $44.45 \%$ cases were of intramural fibroids and $53.34 \%$ cases the size of myoma was $>5 \mathrm{~cm}$. Malpresentation was seen in $15.56 \%$ cases. $75.55 \%$ foetus had normal growth parameter (Table 2).

Table 1: Patient profile $(n=45)$.

\begin{tabular}{|lll|}
\hline Age (in years) & Number & Percentage \\
\hline $20-30$ & 30 & 66.67 \\
\hline $30-40$ & 08 & 17.78 \\
\hline$>40$ & 07 & 15.56 \\
\hline Gravida & 34 & \\
\hline Gravida 1 & 08 & 75.56 \\
\hline Gravida 2 & 03 & 17.78 \\
\hline Gravida 3 or more & & 06.67 \\
\hline Previous surgeries & 06 & \\
\hline Myomectomy & 08 & 13.33 \\
\hline CS & & \\
\hline Anemia status (Hb in gm/dl) & 45 & 100 \\
\hline 10 -12 gm\% & Nil & Nil \\
\hline 8 - 10 gm\% & Nil & Nil \\
\hline$<8$ gm\% & & \\
\hline Associated problems & 07 & 15.56 \\
\hline Pregnancy induced hypertension & 03 & 06.67 \\
\hline Gestational diabetes mellitus & Nil & Nil \\
\hline Bleeding disorder & & \\
\hline Antepartum hemorrhage & 10 & 22.22 \\
\hline Placenta previa & 03 & 06.67 \\
\hline Abruptio placenta & 04 & 08.89 \\
\hline Placenta accreta & & \\
\hline High risk factors for uterine atony & 02 & 04.44 \\
\hline Multiple pregnancy & 04 & 08.89 \\
\hline Polyhydramnios & 02 & 04.44 \\
\hline Previous history of PPH & 02 & 04.44 \\
\hline Grand multipara & 02 & 04.44 \\
\hline Baby weight> 4 kg & & \\
\hline & & \\
\hline
\end{tabular}

Table 2: Fibroid details (as per antenatal USG) $(n=45)$.

\begin{tabular}{|lll|}
\hline Number of fibroids & Number & Percentage \\
\hline Single & 30 & 66.6 \\
\hline Multiple & 15 & 33.33 \\
\hline Location & & \\
\hline Subserosal & 15 & \\
\hline
\end{tabular}




\begin{tabular}{|lcc|}
\hline Number of fibroids & Number & Percentage \\
\hline Intramural & 12 & 26.67 \\
\hline Anterior wall & 08 & 17.78 \\
\hline Posterior wall & 05 & 11.11 \\
\hline Pedunculated & 05 & 11.11 \\
\hline Fundal & 21 & \\
\hline Size (In Cms) & 21 & 46.67 \\
\hline$<5 \mathrm{~cm}$ & 12 & 26.67 \\
\hline $5-10 \mathrm{~cm}$ & 12 & 26.67 \\
\hline$>10 \mathrm{~cm}$ & & \\
\hline Malpresentation & 03 & 06.67 \\
\hline Breech & 04 & 08.89 \\
\hline Transverse & & \\
\hline Amount of liquor & 03 & 06.67 \\
\hline Polyhydramnios & 05 & 11.11 \\
\hline Oligohydramnios & & \\
\hline Fetus growth parameters & 34 & 75.55 \\
\hline Normal & 10 & 22.22 \\
\hline IUGR & 01 & 02.22 \\
\hline IUD & & \\
\hline
\end{tabular}

Table 3: Intra operative details (all elective LSCS) $(n=45)$.

\begin{tabular}{|lll|}
\hline Gestational age at time of CS (in weeks) & Number & Percentage \\
\hline $24-28$ (Due to red degeneration and torsion of fibroid) & 02 & 04.44 \\
\hline 28-32 (Due to PPROM + fetal malpresentation) & 06 & 13.33 \\
\hline $32-36$ (Pre-term labor pains + obstetric indications) & 12 & 26.67 \\
\hline$>36$ (For obstetric or fetal indications) & 25 & 55.56 \\
\hline Anesthesia & & \\
\hline Spinal & 40 & 88.89 \\
\hline General & 05 & 11.11 \\
\hline Time for LSCS (In minutes) & $20 \pm 5$ & $15-25$ \\
\hline Times for myomectomy (in minutes) & $15 \pm 7$ & \\
\hline Incision & 28 & $08-22$ \\
\hline Single & 12 & 62.22 \\
\hline Two & 05 & 26.67 \\
\hline$>$ Two & 10 & 11.11 \\
\hline Purse string sutures & 45 & 22.22 \\
\hline B- Lynch suture & $400 \pm 100$ & 100 \\
\hline Average blood loss (In ml) & Nil & $300-500$ \\
\hline PPH & 06 & Nil \\
\hline Uterine artery ligation & & 13.33 \\
\hline Weight of myoma (In gms) & 20 & \\
\hline$<100$ & 15 & 44.4 \\
\hline $100-500$ & 08 & 33.33 \\
\hline $500-1000$ & 02 & 17.78 \\
\hline$>1000$ & 07 & 04.44 \\
\hline $\begin{array}{l}\text { Tubectomy (Done in all cases of previous LSCS and willing for } \\
\text { tubectomy) }\end{array}$ & 15.56 \\
\hline
\end{tabular}

Table 4: Post-operative details $(n=45)$.

\begin{tabular}{|lll|}
\hline & Number & Percentage \\
\hline Fever & Nil & Nil \\
\hline Blood transfusion (known case of sickle cell anemia) & 04 & 08.88 \\
\hline Duration of hospital stay (in days) & $5 \pm 1$ & $4-6$ \\
\hline Puerperal Sepsis & Nil & Nil \\
\hline Wound dehiscence & Nil & Nil \\
\hline
\end{tabular}




\begin{tabular}{|c|c|c|}
\hline & Number & Percentage \\
\hline \multicolumn{3}{|l|}{ USG on $7^{\text {th }}$ P.O.D } \\
\hline Sub involution & Nil & Nil \\
\hline Any intra peritoneal collection & Nil & Nil \\
\hline \multicolumn{3}{|l|}{ HPE report } \\
\hline Consistent with leiomyoma without degeneration & 30 & 66.67 \\
\hline With red degeneration & 05 & 11.11 \\
\hline With hyaline degeneration & 10 & 22.22 \\
\hline
\end{tabular}

Table 5: Follow up details $(n=45)$.

\begin{tabular}{|lll|}
\hline Repeat uneventful pregnancy $(\mathbf{n = 1 5})$ & Number & Percentage \\
\hline Delivered by repeat CS & 15 & 33.33 \\
\hline Delivered by vaginal & 15 & 100 \\
\hline Scar healing & Nil & Nil \\
\hline Excellent & 14 & 93.33 \\
\hline Poor* & 01 & 06.67 \\
\hline Fertility aspects (n=45) & 07 & 15.56 \\
\hline Patients underwent tubectomy & 12 & 26.67 \\
\hline Patients opted for single child norm & 02 & 04.44 \\
\hline $\begin{array}{l}\text { Patients with age }>40 \text { years + Grade IV endometriosis } \\
\text { keen for second child }\end{array}$ & 09 & 20.00 \\
\hline $\begin{array}{l}\text { Patients with age <30 years having secondary infertility } \\
\text { and under evaluation for infertility }\end{array}$ & & \\
\hline
\end{tabular}

A total $82.23 \%$ of CS were done at $>32$ weeks gestational age (Table 3). A total $62.22 \%$ myomas were removed through single incision $22.22 \%$ myomas weighed $>500$ gms. Maximum weight of myoma removed was $3 \mathrm{~kg}$. at 24 weeks gestational age due to torsion, red degeneration and with intrauterine foetal demise. Blood transfusion was required in 4 cases of sickle cell anaemia who had sickling crisis (Table 4).

A total $25.92 \%$ patients had uneventful second CS with us with excellent scar healing in $93.33 \%$ cases. $20 \%$ cases had secondary infertility and are advised further evaluation to find cause of infertility (Table 5).

\section{DISCUSSION}

To make CM safe we emphasize that experienced surgeons should perform it. Till date there is no relevant literature to suggest as who should be counted as experienced surgeon. ${ }^{3}$ Our all patients were diagnosed cases of fibroid with pregnancy and it was not incidental finding and all cases were electively planned for LSCS with myomectomy, whereas Mumtaz $\mathrm{P}$ also attempted Myomectomy in incidental cases of $15.4 \% .^{4}$ Large fibroids $>5 \mathrm{~cm}$ are more likely to grow during pregnancy and can cause miscarriages, obstructed labor, malpresentation, pressure symptoms, pain due to red degeneration, pre-term labor, pre-term premature rupture of membranes. These complications also occurred in our cases (Table 2).

In series by Machado et al they reported that 7 patients out of 8 had fibroids $>5 \mathrm{~cm}$ in diameter who underwent CM. $^{5}$ In their series step wise devascularization was required to control PPH in one patient. Pre-operative placement of uterine balloon catheter was used in another patient with a large posterior wall fibroid. The balloon was inflated intra operatively controlling the hemorrhage. None of their patients required hysterectomy.

In our series average blood loss was $400 \pm 100 \mathrm{ml}$. Bala $R$ et al found mean average blood loss of $600.2 \pm 104.2 \mathrm{cc}$ and no patient required Cesarean hysterectomy $(\mathrm{CH}){ }^{6}$ They had applied purse string sutures at the base, secured myoretraction by bimanual massage and intravenous infusion of 5 dose of oxytocin was given to ensure uterine contraction during myomectomy.

Senturk et al also found control of bleeding by suturing the myoma bed and use of oxytocin but in some cases still uterine atony and bleeding occurred requiring hypogastric artery ligation. ${ }^{7}$

We had used prophylactic B-Lynch sutures in all our patients. No atonic PPH occurred in any patient and none of them required hysterectomy. In our series neither the location nor the size of the myoma affected our decision to perform CM. Myoma location in relation to the large blood vessels constitutes a very important factor while deciding to perform CM.

Zhao $\mathrm{R}$ et al found that myomectomy was performed more frequently with sub serous fibroids and was avoided in intramural and cervical fibroids. ${ }^{8}$

The literature offers only one absolute contraindication to $\mathrm{CM}$ i.e. the intra surgical uterine hypotony atony following the delivery of fetus. In addition to anatomical location, the number and size of the fibroid, experience of 
surgeon and suspicious degeneration of the fibroid is important factor influencing decision of CM. Sparic et al removed $77.45 \%$ myomas without degeneration, we removed $66.67 \%$ myomas without degeneration, $11.11 \%$ with red degeneration and $22.22 \%$ with hyaline degeneration. ${ }^{3}$ No case was malignant. Agrawal et al also reported that in their series of 14 women there was no case of histologically proven malignancy. ${ }^{9}$ Mumtaz et al reported degeneration in 3 patients out of 26 patients in their series. ${ }^{4}$ The scar integrity following CM was excellent in $93.3 \%$ cases who underwent repeat CS with us. The review article by Awoleke also suggest that CM scar has better healing than that of interval myomectomy. ${ }^{10}$

In our series there was no added morbidity because of $\mathrm{CM}$ and mortality rates were nil. Celal $\mathrm{K}$ also concluded in their series of 27 patients that there was no increase in morbidity or mortality rates but Kim YS et al reported significant complications like ileus and postoperative atonic bleeding. ${ }^{11,12}$

Jaiswar et al supported the safety of CM even with huge fibroids and recommended that the old practice of avoiding myomectomy along with $\mathrm{CS}$ should be reconsidered Mangla et al showed that blood loss is comparable between CM and abdominal myomectomy. ${ }^{13}$ And CM in case of single fibroid can be safely done in selected patients with proper methods to reduce blood loss. ${ }^{14}$

\section{Limitation of the study}

We had limited number of cases who were diagnosed antenatally with fibroid in the index pregnancy and were willing for myomectomy.

\section{CONCLUSION}

The decision to proceed with elective myomectomy at time of CS should be approached with proper preoperative evaluation of the patient, thorough counseling for hysterectomy if required, expert team, arrangement of blood and adequate correction of medical factors like anemia, hypertension, and diabetes mellitus. We have removed large myomas and our patients were at high risk of PPH because of factors like associated placenta previa, accreta, polyhydramnios, large babies, twin pregnancies]. Prophylactic application of B- Lynch sutures in all the cases made a dramatic improvement in tone of uterus which we observed intra operatively. All the methods which we employed for safe myomectomy are already published in literature and we conclude that $\mathrm{CM}$ is a safe procedure.

\section{Funding: No funding sources} Conflict of interest: None declared

Ethical approval: The study was approved by the Institutional Ethics Committee

\section{REFERENCES}

1. Lee JH, Cho DH, Myomectomy using purse - string suture during cesarean section, Arch Gynecol Obstet. 2011;283(supp-1):35-7.

2. B - Lynch C, Cokar A, Lawal AH, The B- Lynch surgical technique for the control of massive postpartum hemorrhage: an alternative to hysterectomy ? Five cases reported, BJOG. 1997; 104:372-5.

3. Sparic R, Malvasi A, Tinelli A, Analysis of clinical, biological and obstetric factors influencing the decision to perform cesarean myomectomy, Ginekol Pol. 2015;86:40-5.

4. Mumtaz P, Sajan R, Wahab A, Imrana HS. Outcomes of cesarean myomectomy - A retrospective study, JEBMH. 2014;1(5):312-9.

5. Machado LS, Gowri V, Al Riyami N, Al- Kharusi L. Cesarean Myomectomy, Feasibility and Safety, Sultan Qaboos Univ Med J. 2012;12(2):190-6.

6. Bala R, Kamal P, Nagapal M, Singh S. Current status of caesarean section mayomectomy prospective ongoing stydy. Int J Reprod Contracept. Obstet Gynecol. 2019;8(8):3189-93.

7. Sentruk MB, Polat M, Dogan O, Pulatoglu C, Yardimci OD, Karakus R and Tayyar AT. Outcome of Cesearean Myomectomy :Is it a Safe Precedure? Geburtshilfe Frauenheilkd. 2017;77(11):1200-6.

8. Zhao R,Wang X, Zou L, Zhang W, Outcomes of Myomectomy at the Time of Cesarean Section among Pregnant Women with Uterine Fibroids. A Retrospective Cohort study, BioMed Research Int. 2019.

9. Agrawal K, Agrawal L, Agrawal A, Agrawal VK, Agrawal K. Cesarean Myomectomy: Prospective Study. NJIRM. 2011;2(3):11-4.

10. Awoleke J.O, Myomectomy during cesarean birth in Fibroid- Endemic, Low- Resource settings, Obstet Gynecol Int J. 2013;1-6.

11. Celal K, Holya C, The evaluation of myomectomies performed during cesarean section in our clinic, Niger Med J. 2011;52(3):186-8.

12. Kim YS, Choi SD, Bae DH, Risk factors for complications in patients undergoing myomectomy at the time of cesarean section. J Obstet Gynaecol Res. 2010;36:550-4.

13. Jaiswar SP, Srivastava P, Priyadarshan A, Deo S, Shankhwar P, Safety of Cesarean Myomectomy with huge myoma uncomplicated cesarean section in indian scenario, Int $\mathbf{J}$ Reprod Contracept Obstet Gynecol. 2015,4(6):1696-9.

14. Mangala KJ, Sudha S, Sarala S, Rajammal B, Usha MG, Sheejamol VS. Comparative Study of Cesarean Myomectomy with Abdominal Myomectomy in Terms of Blood Loss in Single Fibroid, J Obstetrics Gynecol India. 2016;66(4):287-91.

Cite this article as: Agrawal $\mathrm{P}$, Agrawal R, Lobo A, Chandrakar J. Making caesarean myomectomy safe and feasible: a 12 year single center experience. Int J Reprod Contracept Obstet Gynecol 2021;10:899-904. 